\title{
Formation of Nanostructures on the Surface of $\mathrm{CdBr}_{2}$ and $\mathrm{PbI}_{2}$ Crystals
}

\author{
Rovetskyi I.M., Bolesta I.M. \\ Ivan Franko National University of Lviv \\ 107 Tarnavskogo str., \\ Lviv, Ukraine \\ e-mail: rovetskii.ivan@gmail.com
}

\begin{abstract}
By using atomic force microscopy, the surface morphology of $\mathrm{CdBr}_{2}$ and $\mathrm{PbI}_{2}$ crystals was investigated close to the thermodynamic equilibrium. Results of the performed studies indicate that three types of nanostructures are formed on the $\mathrm{CdBr}_{2}$ surface: triangle-shaped nanopores, nanoislands and nanowires. Principal morphological features, such as radius, height and average distance to nearest neighbor are analyzed. Time evolution of the nanostructures formation on $\mathrm{CdBr}_{2}$ surface shows that nanopores and nanoislands are formed during first $\mathbf{7 2}$ hours of aging in air. During next 72 hours nanowires are formed. No signatures confirming the formation of nanostructures on the $\mathrm{PbI}_{2}$ crystal surface were detected.
\end{abstract}

Index Terms-nanostructures, nanoclusters, nanopores, nanowires.

\section{INTRODUCTION}

$\mathrm{CdI}_{2}$ crystals are promising scintillators with relaxation time of $\tau<1 \mathrm{~ns}$ for detectors of ionizing radiation and potential candidates for optical recording due to photochromic properties. AFM studies of $\mathrm{CdI}_{2}$ indicated that aging of crystals in air leads to the formation of cadmium oxide and cadmium hydroxide. [1-3].

In order to investigate the influence of cation and anion subsystems on the formation of surface nanostructures in $\mathrm{CdI}_{2}$, time dynamics of surface nanostructures evolution in $\mathrm{CdBr}_{2}$ and $\mathrm{PbI}_{2}$ was studied. $\mathrm{CdBr}_{2}$ and $\mathrm{CdI}_{2}$ crystals have same $\mathrm{Cd}^{2+}$ cation and different anions, whereas $\mathrm{PbI}_{2}$ and $\mathrm{CdI}_{2}$ crystals have same $\mathrm{I}^{-}$anion and different cations.

\section{AFM STUDIES}

AFM images showing the surface morphology of $\mathrm{CdBr}_{2}$ surface after aging in air during 24 hours indicates the formation of nanostructures - triangle-shaped nanopores (A, C Fig. 1, $a$ ) and clusters (B Fig.1, a).

Depth of A and C nanopores is становить 150 та $128 \mathrm{~nm}$ (Fig. 1, $a, c$ ), respectively. On the surfaces of crystals, these nanopores form equilateral triangles, with 1.2 and $1.3 \mathrm{mkm}$ dimensions, respectively. Triangle shape of pores is due to rhombohedral crystalline structure of $\mathrm{CdBr}_{2}$.

Aging of $\mathrm{CdBr}_{2}$ over 72 hours is accompanied by the formation of island-like nanostructures (Fig. 2). Lateral dimensions and heights are within $200 \mathrm{~nm} \div 2 \mathrm{mkm}$ and $10 \div$ $120 \mathrm{~nm}$, respectively (table 1).

Distances between nanoiclusions are typically much larger that their sizes and fall within $1 \div 1.5 \mathrm{mkm}$ (table 1 ), that may confirm the absence of interaction between them at this stage of the formation. Besides, distance distribution is Gaussianshaped that speaks in favour of stochastic nature of the formation.

During aging of $\mathrm{CdBr}_{2}$ in air for 148 hours, the number of triangular pores (fig. 3.15,a) and nanowires (fig. 3.15,c) on its surface substantially increases. Depth and lateral dimensions of nanopores are within $50 \div 170 \mathrm{~nm}$ and $1 \div 1.8$ mkm, respectively (fig. 3, $b, d$ ).

The formation of nanowires on $\mathrm{CdBr}_{2}$ surface occurs due to nanocluster aggregation (fig. 3, $a$ ). For example, from the nanowire profile (fig. 2, b) one can see that nanostructure of this type consist at least of for smaller nanostructures with lateral dimensions around $100 \mathrm{~nm}$ and heights of 8.6 and 10 nm.

It is established, that the number of nanopores formed on $\mathrm{CdBr}_{2}$ surface increases with time of aging in air. Therefore, it is most likely that they are formed due to dissolving of $\mathrm{CdBr}_{2}$ during the condensation of moisture on the surface.

The surface of freshly cleaved $\mathrm{PbI}_{2}$ crystals shows steps with atomically flat zones in between. (fig. $4 a$ ). Based on the analysis of the autocorrelation function profile, one can estimate the roughness which equals to $1 \mathrm{~nm}$ (fig. $4 \mathrm{~b}$ ). Such value of roughness is due to steps that are formed in the process of cleaving. Additional maxima in the autocorrelation function profile (A, A', B and B') indicate the formation of quasiperiodic structures with the period of $1.3 \mathrm{mkm}$.

Aging of $\mathrm{PbI}_{2}$ in air atmosphere does not stimulate the growth of nanostructures on the surface.

\section{CONCLUSIONS}

Thus, aging of $\mathrm{CdBr}_{2}$ in air promotes the formation of triangular nanopores, island-like nanoclusters and nanowires. Studies of the time evolution of the formation of nanostructures on $\mathrm{CdBr}_{2}$ surface during aging in air for 1 week indicated that at the same thermodynamic conditions nanostructures grow faster than in $\mathrm{CdI}_{2}$ crystals. It is connected with higher chemical activity of $\mathrm{Br}^{-}$anion as compared to $\mathrm{I}^{-}$. Obtained AFM data show that the formation of nanostructures is more intensive in $\mathrm{CdI}_{2}$ as compared to $\mathrm{PbI}_{2}$ and even more intensve for $\mathrm{CdBr}_{2}$. From the comparison of the time evolution of the formation of nanostructures on $\mathrm{CdI}_{2}$, $\mathrm{CdBr}_{2}$ and $\mathrm{PbI}_{2}$ surfaces one can conclude that $\mathrm{Cd}^{2+}$ cation and $\mathrm{I}^{-}$anion participate in the process. 


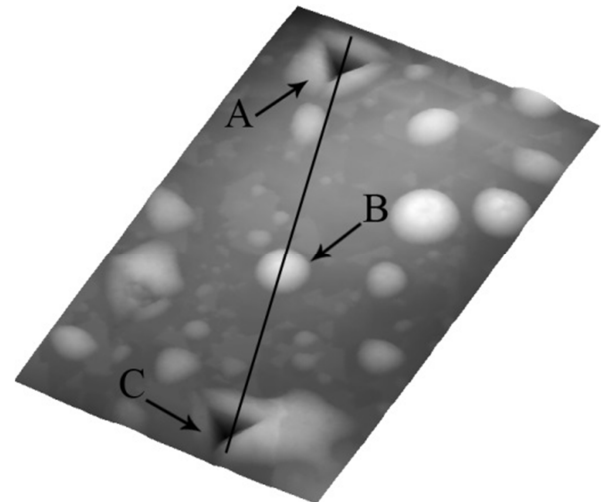

a)

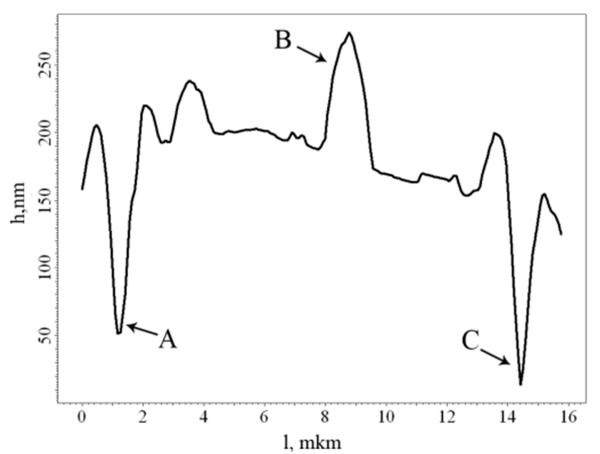

b)

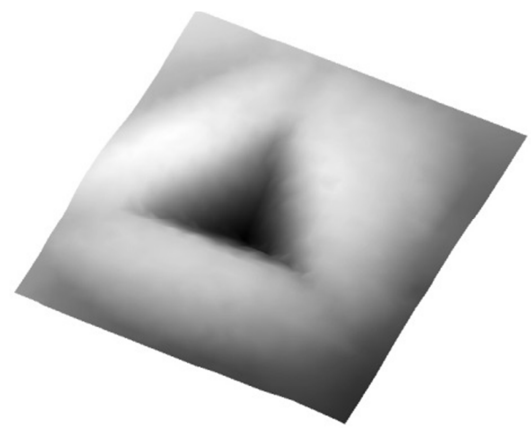

c)

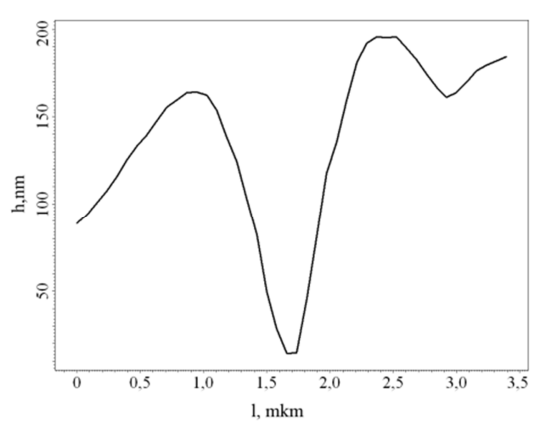

d)

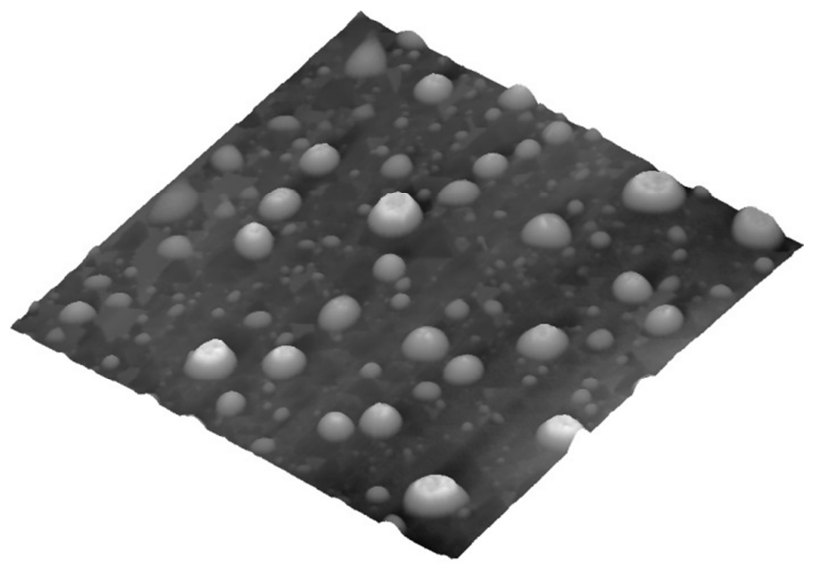

a)

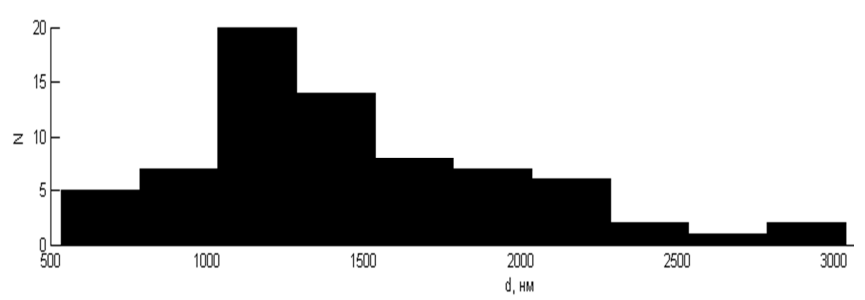

b)

Fig. 2. Nanostructures formed on the surface of $\mathrm{CdBr}_{2}$ crystals during their aging in air or 72 hours $(a)$; розподіли the distribution of distances between nanostructures (area size: 17x20 mkm; height range: $170 \mathrm{~nm}$ )

TABLE 1. NUMERICAL ANALYSIS OF CLUSTERS, FORMED ON THE SURFACE OF $\mathrm{CdBr}_{2}$ CRYSTALS DURING THEIR AGING IN AIR FOR 72 HOURS.

\begin{tabular}{|c|c|c|}
\hline № & $\begin{array}{c}\text { Cluster } \\
\text { parameter }\end{array}$ & Value \\
\hline 1 & number & 72 \\
\hline 2 & min radius, nm & 108 \\
\hline 3 & $\begin{array}{c}\text { max radius, } \\
\text { mkm }\end{array}$ & 1.2 \\
\hline 4 & $\begin{array}{c}\text { average radius, } \\
\text { nm }\end{array}$ & 431 \\
\hline 5 & $\begin{array}{c}\text { min height, nm } \\
\text { max height, nm }\end{array}$ & 123 \\
\hline 6 & $\begin{array}{c}\text { average height, } \\
\text { nm }\end{array}$ & 38 \\
\hline 7 & $\begin{array}{c}\text { average distance } \\
\text { between } \\
\text { nanostructures, } \\
\text { mkm }\end{array}$ & 1.5 \\
\hline \multicolumn{2}{|c|}{} & \\
\hline 8 & & \\
\hline
\end{tabular}

Fig. 1. ACM images of nanostructures formed on the surface of $\mathrm{CdBr}_{2}$ crystals during their aging in air for 24 hours. $(a, b)$ and respective profiles $(c, d)$ : $\mathrm{A}, \mathrm{C}$ - nanopores, B - cluster; sizes: $a-15 \times 9 \mathrm{mkm} ; c-2.8 \times 2.4 \mathrm{mkm}$; height range: $a-180 \mathrm{~nm} ; \mathrm{c}-208 \mathrm{~nm}$ ) 


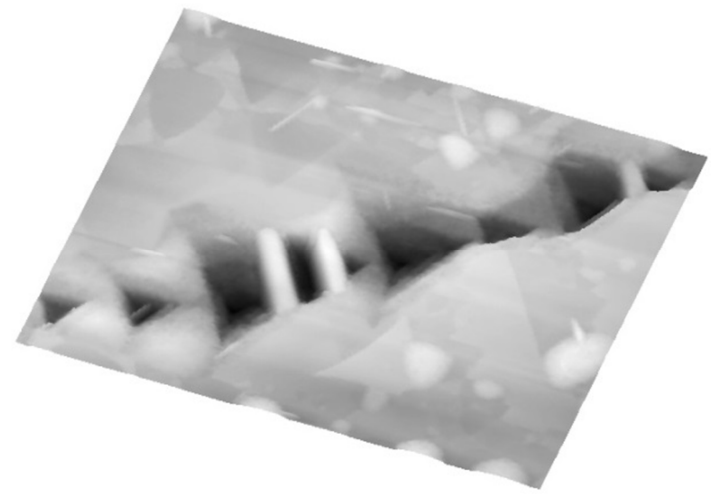

a)

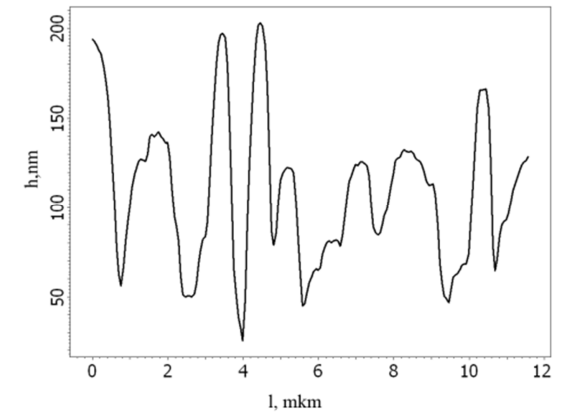

b)

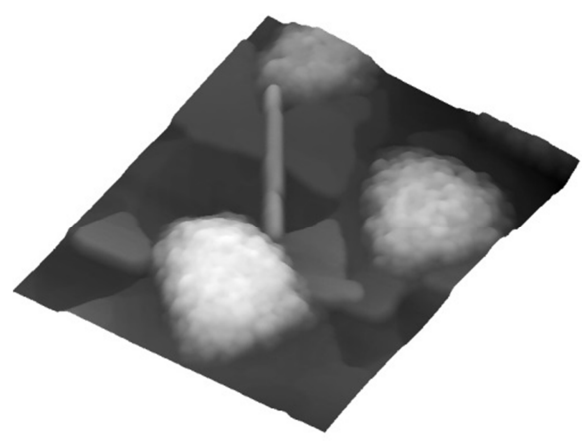

c)

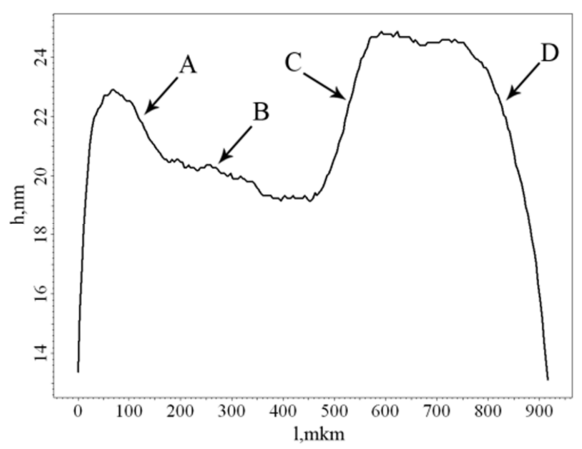

d)

Fig. 3. AFM images of nanostructures formed on $\mathrm{CdBr}_{2}$ crystal surface during aging in air for 168 hours: $a, b$ ) nanopores and their profile; $c, d$ ) nanowire and its profile; (areas sizes: $a-8.5 \times 10 \mathrm{mkm}, c-2.1 \times 1.7 \mathrm{mkm}$; height range: $a-209 \mathrm{~nm}, c-57 \mathrm{~nm})$
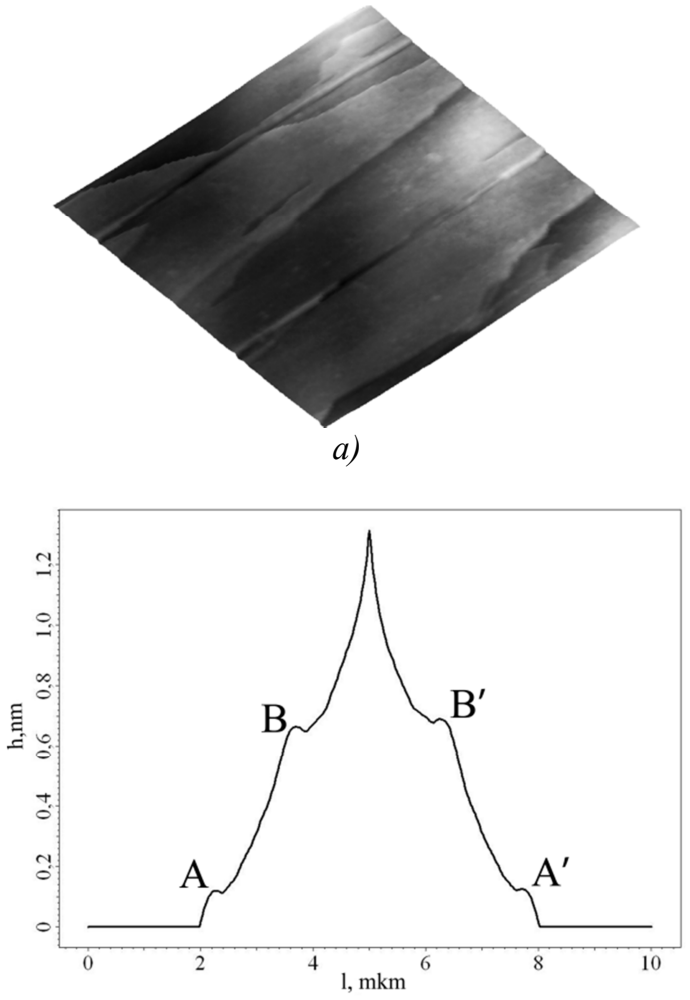

b)

Fig. 4. AFM image of the $\mathrm{PbI}_{2}$ surface morphology during aging in air for 168 hours. (a); autocorrelation function profile (area size: $3 \times 3 \mathrm{mkm}$; height range: $7 \mathrm{~nm})(b)$

\section{REFERENCES}

[1] I. M. Bolesta, I. N. Rovetskyj, M. V. Partyka, I. D. Karbovnyk, B.Ya. Kulyk "Formation of nanostructures on the VdW-surface of CdI2 crystals", Ukr. J. Phys., 2013, vol. 58, pp. 490-496.

[2] I. M. Bolesta, I. N. Rovetskii, Z. M. Yaremko, I. D. Karbovnyk, S. R. Velgosh, M. V. Partyka, N. V. Gloskovskaya, V. M. Lesivtsiv . "On the mechanism of nanostructure growth on the surface of CdI2 crystals", Ukr. J. Phys., 2015, vol. 6, pp. 1143-1149/

[3] I. M. Bolesta, I.N. Rovetskii, I. D. Karbovnyk, S.V. Rykhlyuk, M. V. Partyka, N. V. Gloskovskaya "Formation and Optical Properties of CdI2 Nanostructures", Journal of Applied Spectroscopy, 2015, vol. 82 , pp. 84-90. 